\title{
Heart failure and the prognostic impact and incidence of new-onset of diabetes mellitus: a nationwide cohort study
}

\author{
B. Zareini ${ }^{*}$, Rasmus Rørth², Anders Holt ${ }^{1}$, Ulrik M. Mogensen², Christian Selmer ${ }^{3}$, Gunnar Gislason?, \\ Morten Schou ${ }^{1}$, Lars Køber ${ }^{2}$, Christian Torp-Pedersen ${ }^{4,5}$, Morten Lamberts ${ }^{1}$ and Søren Lund Kristensen ${ }^{2}$
}

\begin{abstract}
Background: Prevalent diabetes at the time of heart failure (HF) diagnosis is associated with a higher risk of death, but the incidence and prognostic importance of new-onset diabetes in patients with established HF remains unknown.

Methods: Patients with a first hospitalization for HF in the period 2003-2014 were included and stratified according to history of diabetes. Annual incidence rates of new-onset diabetes were calculated and time-dependent multivariable Cox regression models were used to compare the risk of death in patients with prevalent and new-onset diabetes with patients without diabetes as reference. The model was adjusted for age, sex, duration of HF, educational level and comorbidity. Covariates were continuously updated throughout follow-up.
\end{abstract}

Results: A total of 104,522 HF patients were included in the study, of which 21,216 (19\%) patients had diabetes at baseline, and 8164 (10\%) developed new-onset diabetes during a mean follow-up of 3.9 years. Patients with new-onset diabetes and prevalent diabetes were slightly younger than patients without diabetes (70 vs. 74 and 77 , respectively), more likely to be men (62\% vs. $60 \%$ and $54 \%$ ), and had more comorbidities expect for ischemic heart disease, hypertension and chronic kidney disease which were more prevalent among patients with prevalent diabetes. Incidence rates of new-onset diabetes increased from around 2 per 100 person-years in the first years following HF hospitalization up to 3 per 100 person-years after 5 years of follow-up. A total of 61,424 (59\%) patients died during the study period with event rates per 100 person-years of 21.5 for new-onset diabetes, 17.9 for prevalent diabetes and 13.9 for patients without diabetes. Compared to patients without diabetes, new-onset diabetes was associated with a higher risk of death (adjusted HR 1.47; 95\% Cl 1.42-1.52) and prevalent diabetes was associated with an intermediate risk (HR 1.19; 95\% Cl, 1.16-1.21).

Conclusion: Following the first HF hospitalization, the incidence of new-onset diabetes was around 2\% per year, rising to 3\% after 5 years of follow-up. New-onset diabetes was associated with an increased risk of death, compared to HF patients with prevalent diabetes (intermediate risk) and HF patients without diabetes.

Keywords: Heart failure, Type 2 diabetes mellitus, Prognosis

\footnotetext{
*Correspondence: bochrazareini@gmail.com

1 Department of Cardiology, Herlev and Gentofte University Hospital,

Niels Andersens vej 65, Gentofte, 2900 Copenhagen, Denmark

Full list of author information is available at the end of the article
} 


\section{Background}

Heart failure (HF) and diabetes frequently co-exist and in the most contemporary trials of heart failure, one out of three patients had a history of diabetes [1]. Hyperglycemia has been associated with changes in cardiac structure, cardiac function, increased atherosclerosis, and the existence of a specific diabetic cardiomyopathy phenotype has been suggested [2-4]. Conversely, HF has been associated with insulin resistance and hyperglycemia in a severity-dependent manner [5-7]. Despite previous studies establishing the detrimental prognosis of patients with HF and diabetes, the interplay of this bidirectional relationship has not been fully elucidated Specifically, the mortality risk associated with new-onset diabetes vs. prevalent diabetes in patients with HF has never been investigated. Our purpose was to investigate the incidence of new-onset diabetes following a diagnosis of HF and compare its prognostic impact on the risk of death with that of HF patients with prevalent diabetes and without diabetes.

\section{Methods}

\section{Data sources}

In Denmark, every resident is assigned a unique personal identification number enabling individual-level linkage between nationwide health care registries. The Danish National Patient Registry entails information on all hospital admissions from 1978 and forward. Each hospital contact is coded with a primary diagnosis and several secondary diagnoses according to The International Classification of Disease, Eighth Revision (ICD-8) until 1993, and The International Classification of Disease, Tenth Revision (ICD-10) from 1994 onwards. The Danish National Prescription Registry holds information (dosage, dates, and Anatomical Therapeutic Chemical (ATC) codes on all prescriptions dispensed from a pharmacy since 1995 and the Danish Civil Registration System records vital-status.

\section{Study population}

We included adults (older than 18 years) with a firsttime diagnosis of HF in hospital discharge records in the period 2003-2014. The index date (date of inclusion) was 30 days after discharge from the hospital.

\section{Definition of diabetes status}

Prevalent diabetes was defined by at least one prescription of a glucose-lowering drug and/or a previous ICD code of diabetes 6 months prior to the index date. Newonset diabetes was defined by a first claimed prescription of a glucose-lowering drug and/or an ICD code of diabetes after index date in patients with no prior history of diabetes. Combining the use of ICD codes and prescriptions to assess diabetes status have been validated previously with a positive predictive value of $97 \%$ and $95 \%$, respectively [8-10].

\section{Definition of comorbidities and medical therapy}

Comorbidities were identified through ICD codes from hospital records up to 10 years prior to the index date, and continuously updated throughout the followup period (see Appendix: Table 2 for details and ICD codes). Information on concomitant medical therapy was obtained from dispensed prescriptions as listed in the Danish National Prescription Registry and defined by at least one redeemed prescription of the drug 6 months prior to the index date. The following drugs were recorded at inclusion baseline: angiotensin-converting enzyme inhibitors (ACE), angiotensin II receptor blockers (ARB), calcium channel blockers, loop diuretics, thiazides, digoxin, platelet inhibitors (acetylic acid and adenosine diphosphate receptor inhibitor), mineralocorticoid receptor antagonists (MRA), statins, beta-blockers, insulin, metformin, sulfonylurea, thiazolidinedione (TZD), dipeptidyl peptidase-4 (DPP-4) inhibitor, glucagon-like peptide-1 (GLP-1) receptor agonist, sodium-glucose cotransporter-2 (SGLT2) inhibitor and patients who treated with a combination of two anti-diabetic drugs. DPP-4 inhibitors, GLP-1 receptor agonists and SGLT2 inhibitors were combined in one group defined as newer antidiabetic medication for further statistical analysis (see Appendix: Table 2 on details regarding details and ATC codes).

\section{Outcome measures}

The outcomes of the study were new-onset diabetes and all-cause death. Patients were followed to new-onset diabetes, death, emigration or end of study (31 December 2015).

\section{Statistics}

Baseline characteristics were described by the use of proportions for categorical variables with means and standard deviations (SD) or medians and interquartile ranges (IQR) for continuous variables. Differences between groups were tested by use of the Chi square test for categorical variables, non-parametric test for non-normally distributed continuous variables and parametric for normally distributed continuous variables. Annual incidence rates of newonset diabetes were calculated per 100 person-years. In analyses of all-cause death, we treated new-onset diabetes as a time-dependent variable and compared the risk with prevalent diabetes patients and patients free of diabetes as reference. To account for the longer duration of $\mathrm{HF}$ in patients with 
new-onset diabetes, follow-up time was split into 1 -year intervals from inclusion date, and according to calendar year in 3-year intervals. These variables were included in the adjusted model. Comorbidity and antidiabetic medication were continuously updated throughout follow-up, and age was updated at the beginning of each interval. A multivariable Cox proportional hazards analysis was performed to compare hazard ratios of death according to diabetes status. The model was adjusted for age, sex, duration of HF, education level and each individual comorbidity (ischemic heart disease, cancer, atrial fibrillation, chronic obstructive pulmonary disease, chronic kidney disease, hypertension, and stroke). To compare new-onset diabetes to prevalent diabetes, we repeated the analysis, but used prevalent diabetes status as the reference and included antidiabetic medication (metformin, insulin, TZD, sulfonylurea and newer anti-diabetic drugs consisting of DPP-4 inhibitors, SGLT2-inhibitors, and GLP-1 receptor agonists) in the model. Tests for interactions of diabetes status and sex in relation to risk of death were performed. Analyses were performed using SAS (version 9.4 for Windows, SAS Institute, North Carolina) and R (version 3.5.0 for Windows, R Foundation for Statistical Computing) [11].

\section{Results}

Of 104,522 HF patients included in the study, 21,216 (19\%) patients had diabetes at baseline, and 8164 (10\%) patients without diabetes at baseline developed newonset diabetes during the follow-up period (Fig. 1). Patient characteristics of all three groups are shown in Table 1 (with the baseline for the new-onset diabetes group being time of diabetes diagnosis). Patients with new-onset diabetes and prevalent diabetes were slightly younger than patients without diabetes (70 vs. 74 and 77 , respectively), more likely to be men (62\% vs. $60 \%$ and $54 \%$ ), and had more comorbidities except for ischemic heart disease, hypertension and chronic kidney disease which were more present in patients with prevalent diabetes All evaluated pharmacotherapy, including evidence-based HF medication was more widely used among patients with prevalent diabetes than in patient with new-onset or no diabetes except for beta blockers (68\% vs. $63 \%$ vs. \%), digoxin ( $34 \%$ vs. $22 \%$ vs. $24 \%$ ) and MRA ( $32 \%$ vs. $28 \%$ vs. $23 \%)$ which were more likely to be given to patients with new-onset diabetes. Patients with prevalent diabetes were more likely to be treated with all types of antidiabetic medications except for metformin which was more likely to be prescribed to patients with newonset diabetes ( $54 \%$ vs. $44 \%)$. The comparisons are at

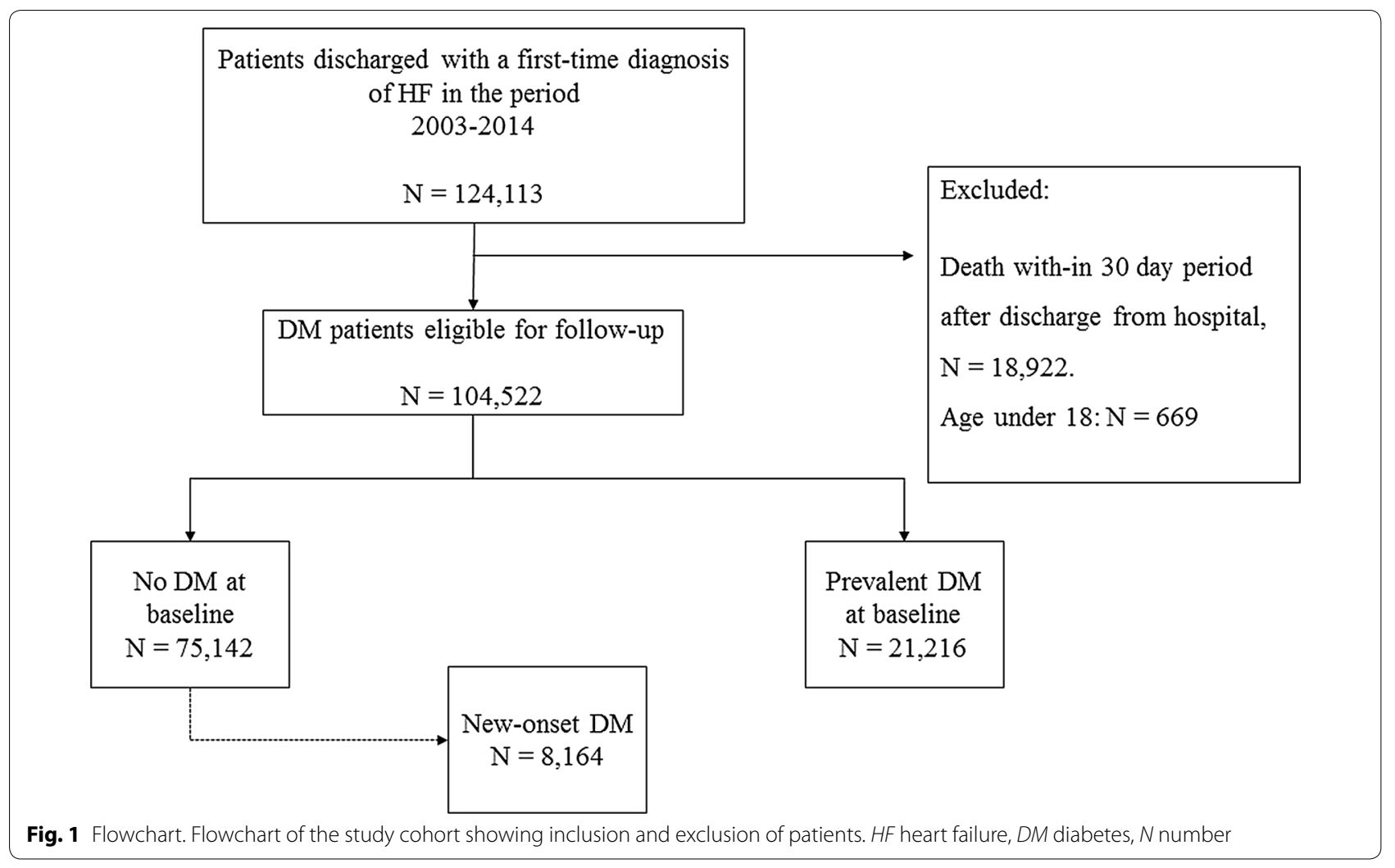


Table 1 Patient characteristics of HF patients at inclusion according to diabetes

\begin{tabular}{|c|c|c|c|c|c|}
\hline Variable & No diabetes & Prevalent diabetes & New-onset diabetes & Total & $\mathrm{p}$-value \\
\hline Number of individuals & 75,142 & 21,216 & 8164 & 104,522 & \\
\hline Age (median with IQR) & $77.0(18.0,109.0)$ & $74.0(22.0,103.0)$ & $70.0(18.0,100.0)$ & $76.0(18.0,109.0)$ & $<1 \mathrm{e}-04$ \\
\hline \multicolumn{6}{|l|}{ Comorbidities } \\
\hline Sex & $40,733(54.2)$ & $12,726(60.0)$ & $5056(61.9)$ & $58,515(56.0)$ & $<1 \mathrm{e}-04$ \\
\hline$I H D$ & $40,621(54.1)$ & $14,071(66.3)$ & $5272(64.6)$ & $59,964(57.4)$ & $<1 \mathrm{e}-04$ \\
\hline Atrial fibrillation & $36,133(48.1)$ & $9848(46.4)$ & $4634(56.8)$ & $50,615(48.4)$ & $<1 \mathrm{e}-04$ \\
\hline Cancer $^{*}$ & $18,323(24.4)$ & $4850(22.9)$ & $2021(24.8)$ & $25,194(24.1)$ & $<1 \mathrm{e}-04$ \\
\hline COPD & $20,575(27.4)$ & $6532(30.8)$ & $2834(34.7)$ & $29,941(28.6)$ & $<1 \mathrm{e}-04$ \\
\hline Hypertension & $37,862(50.4)$ & $15,499(73.1)$ & $5497(67.3)$ & $58,858(56.3)$ & $<1 \mathrm{e}-04$ \\
\hline CKD & $11,521(15.3)$ & $6193(29.2)$ & $1886(23.1)$ & $19,600(18.8)$ & $<1 \mathrm{e}-04$ \\
\hline \multicolumn{6}{|l|}{ Pharmacotherapy } \\
\hline Statin & $27,578(36.7)$ & $13,242(62.4)$ & $4967(60.8)$ & $45,787(43.8)$ & $<1 \mathrm{e}-04$ \\
\hline ACE/ARB & $47,434(63.1)$ & $16,246(76.6)$ & $5497(67.3)$ & $69,177(66.2)$ & $<1 \mathrm{e}-04$ \\
\hline Beta blockers & $44,446(59.1)$ & $13,437(63.3)$ & $5522(67.6)$ & $63,405(60.7)$ & $<1 \mathrm{e}-04$ \\
\hline Digoxin & $17,873(23.8)$ & $4687(22.1)$ & $2731(33.5)$ & $25,291(24.2)$ & $<1 \mathrm{e}-04$ \\
\hline ADP & $44,409(59.1)$ & $14,943(70.4)$ & $4834(59.2)$ & $64,186(61.4)$ & $<1 \mathrm{e}-04$ \\
\hline Loop diuretics & $53,114(70.7)$ & $16,764(79.0)$ & $5763(70.6)$ & $75,641(72.4)$ & $<1 \mathrm{e}-04$ \\
\hline MRA & $17,211(22.9)$ & $5991(28.2)$ & $2635(32.3)$ & $25,837(24.7)$ & $<1 \mathrm{e}-04$ \\
\hline Thiazide & $15,222(20.3)$ & $4316(20.3)$ & $989(12.1)$ & $20,527(19.6)$ & $<1 \mathrm{e}-04$ \\
\hline Ca channel blockers & $17,478(23.3)$ & $7403(34.9)$ & $1843(22.6)$ & $26,724(25.6)$ & $<1 \mathrm{e}-04$ \\
\hline Insulin & & $6999(33.0)$ & $825(10.1)$ & $7824(7.5)$ & $<1 \mathrm{e}-04$ \\
\hline Metformin & & $9340(44.0)$ & $4425(54.2)$ & $13,765(13.2)$ & $<1 \mathrm{e}-04$ \\
\hline Sulfonylurea & & $6859(32.3)$ & $1239(15.2)$ & $8098(7.7)$ & $<1 \mathrm{e}-04$ \\
\hline Thiazolidinedione & & $82(0.4)$ & $5(0.1)$ & $87(0.1)$ & $<1 \mathrm{e}-04$ \\
\hline DPP-4 inhibitors & & $574(2.7)$ & $264(3.2)$ & $838(0.8)$ & $<1 \mathrm{e}-04$ \\
\hline GLP-1 receptor agnoists & & $1(0.0)$ & $28(0.3)$ & $29(0.0)$ & $<1 \mathrm{e}-04$ \\
\hline SGLT2 inhibitors & & $1(0.0)$ & $8(0.1)$ & $9(0.0)$ & $<1 \mathrm{e}-04$ \\
\hline $\begin{array}{l}\text { Newer antidiabetic drugs: } \\
\text { DPP-4, GLP-1 and SGLT2 } \\
\text { combined }\end{array}$ & & $576(0.5)$ & $294(0.3)$ & $870(0.8)$ & $<1 \mathrm{e}-04$ \\
\hline $\begin{array}{l}\text { Combination of two antidia- } \\
\text { betic drugs }\end{array}$ & & $427(2.0)$ & $78(1.0)$ & $505(0.5)$ & $<1 \mathrm{e}-04$ \\
\hline
\end{tabular}

$D M$ diabetes mellitus, IQR interquartile range, IHD ischemic heart disease, COPD chronic obstructive pulmonary disease, $C K D$ chronic kidney disease, $A C E$ angiotensin inhibitor medication, $A R B$ angiotensin II receptor blockers, MRA mineralocorticoid receptor antagonists, DPP-4 dipeptidyl peptidase-4, GLP-1 glucagon-like peptide-1, SGLT2 sodium-glucose-cotransporter-2

* All cancers, excluding non-melanoma skin cancers

least, partly skewed by the fact that baseline for the new-onset diabetes was after a mean HF duration of 3.2 years as compared to the time of HF diagnosis in the two other groups.

\section{New-onset diabetes}

During a mean follow-up of 3.9 years, 8164 (10\%) developed new-onset diabetes yielding an event rate of 2.5 per 100 person-years. Over time, annual incidence rates of new-onset diabetes increased from around 2 per 100 person-years in the first years following HF hospitalization up to 3 per 100 person-years after 5 years of follow-up (Fig. 2).

\section{All-cause death}

A total of 61,424 (59\%) patients died during the study period, with an event rate of 15.0 per 100 person-years. Rates were lowest among patients without diabetes (13.9 per 100 person-years), intermediate in those with prevalent diabetes (17.9 per 100 person-years) and highest among patients with new-onset diabetes (21.5 per 100 person-years). In age- and sex-adjusted analyses this yielded hazard ratios (HR) of 1.46 (95\% CI 1.43-1.49) for prevalent diabetes and HR 1.86 (95\% CI 




Fig. 2 Annual incidence rates of new-onset DM per 100 py of follow-up. The annual crude incidence rates of patients with HF and new-onset diabetes with error bars indicating $95 \%$ confidence interval

1.78-1.91) for new-onset diabetes with patients with HF and no diabetes as reference. In adjusted analyses additionally including education level, and continuously updated duration of HF and comorbidity, the risk estimates were somewhat lower with HR 1.19 (95\% CI 1.16-1.21) for prevalent diabetes and HR 1.47 (95\% CI 1.42-1.52) for new-onset diabetes (Fig. 3). Including antidiabetic medication (metformin, insulin, sulfonylurea, and newer anti-diabetic drugs) and comparing prevalent diabetes patients directly with new-onset diabetes patients in the adjusted model, we found a significantly higher risk estimate for patients with new-onset diabetes HR 1.24 (95\% CI 1.20-1.29). We found no interaction between diabetes status and sex in relation to the risk of all-cause death $(\mathrm{p}=0.229)$.

\section{Discussion}

In this nationwide cohort study including more than 100,000 patients with HF on the impact of prevalent and new-onset diabetes, we have two key findings: First, the annual incidence of new-onset diabetes was approximately $2 \%$ in the first years after HF diagnosis and rising to around 3\% after 5 years of HF duration. Second, HF patients with new-onset diabetes had a markedly elevated risk of death, compared to HF patients without diabetes and with intermediate risk in HF patients with prevalent diabetes.

\section{Relationship between diabetes and development of $\mathrm{HF}$}

The association between diabetes and HF has been well established and reproduced in several observational cohorts. Diabetes is associated with an up to four times increased risk of HF when compared to a general population without diabetes [12]. It is not clear whether this is due to shared risk factors for the two conditions or the presence of a specific diabetic cardiomyopathy, where pathophysiological mechanisms related to abnormal cardiac handling of glucose has been suggested to lead to both systolic and diastolic dysfunction $[4,13]$. The high incidence of $\mathrm{HF}$ in patients with diabetes, even when coronary artery disease is absent, suggests a substantial direct relation between diabetes and development of HF [13]. The higher mortality associated with prevalent diabetes in this study correlates with previous studies describing diabetes as an independent risk factor for death and adverse cardiovascular outcomes in patients with HF $[1,12,14-17]$. Obesity is closely related to diabetes and its presence in patients with diabetes is associated with an increased risk of developing HF, but surprisingly reduced mortality [18]. In established HF, this socalled obesity paradox of reduced mortality exists for patients without diabetes but was not found in patients with diabetes [19]. Our finding of a poorer prognosis in HF patients with incident diabetes is in line with a prior study which showed a graded relation between blood 
glucose levels at the time of hospitalization for HF and long-term outcomes in patients without known diabetes [20]. An older study using Danish registry data showed that mortality risk in HF patients was lower in women, but we found no interaction between diabetes status, sex and mortality risk in the present analysis [21].

\section{Prevalent $\mathrm{HF}$ and diabetes}

The stepwise increase in the incidence of diabetes as HF persists in our study is consistent with the hypothesis that HF over time can lead to diabetes. Apart from including real-world patients, our study highlights important information on how the annual incidence changes over time and similar to that reported from clinical trials [22-25]. Several studies have shown that insulin sensitivity decreases as HF progresses. In the Bezafibrate Infarction Prevention study development of diabetes among HF patients occurred in a stepwise manner from $13 \%$ in New York Heart Association (NYHA) Class I to $20 \%$ in NYHA Class III during a mean follow-up of 7.7 years. Being in NYHA Class III was an independent risk factor for the development of diabetes [26]. Furthermore in patients with advanced HF, left ventricular assist device implantation have been shown to improve diabetes control [27]. In this cohort of real-life patients with $\mathrm{HF}$, around $10 \%$ of patients without diabetes at baseline, developed new-onset diabetes during follow-up, which is similar to findings from the Carvedilol Or Metoprolol European Trial (COMET) where around $10-12 \%$ developed diabetes during 5 years of follow-up [22]. Prior observational studies have demonstrated that increasing HF severity (as defined by dosages of loop diuretics) is associated with new-onset diabetes in a severity-dependent manner [7,28]. The decreased cardiac output as seen in progressive HF may lead to diminished oxygen, glucose and insulin distribution to peripheral muscular tissue as well as a loss of muscle mass which in turn may increase insulin resistance [29]. Impaired blood flow can increase systemic levels of adrenaline (epinephrine) and noradrenaline (norepinephrine) which is suggested to increase insulin resistance and hepatic gluconeogenesis as well as decrease the insulin release from pancreatic beta cells. Sympathetic overdrive has also been shown to reduce insulin sensitivity $[5,30]$. This relation between HF and incident diabetes has been supported by observational studies $[7,26]$. The bidirectional relationship between diabetes and HF is supported by several clinical and epidemiological studies, but the causality remains unclear. The idea of a common disease origin, in a recent review, proposes inflammation and oxidative stress could be the common ground for the development of both diabetes and cardiovascular disease [31].
Targeted anti-inflammatory therapy decreased the risk of recurrent cardiovascular events in patients with known cardiovascular disease and several studies showed novel genetic variants linked to increased risk of both diabetes and cardiovascular disease development [32-34].

\section{Antidiabetic medication and cardiovascular risk}

As expected, patients with new-onset diabetes were not primarily prescribed insulins, thiazolidinediones or DPP-4 inhibitors as these drugs are usually used as addons with the progression of diabetes. Only rarely insulin is used as first-line treatment in patients diagnosed with severely dysregulated diabetes. Likewise, among patients with prevalent diabetes, we found a higher prevalence of all types of antidiabetic drugs, as these patients have had their diabetes for a longer period and therefore often require second-line antidiabetics. In our crude analysis, the risk of death among patients with new-onset diabetes was significantly different and attenuated compared to patients with prevalent diabetes and no diabetes. After adjustment for age, sex, duration of HF, baseline comorbidities and antidiabetic medication, the risk was higher among patients with new-onset diabetes. The cardiovascular safety profile for antidiabetic drugs in patients has been questioned. Overly aggressive antidiabetic therapy may lead to hypoglycemia, and both insulin, as well as thiazolidinediones, can lead to fluid retention and worsening of HF [13, 35]. Compared to SGLT2 inhibitors DPP-4 inhibitors were associated with increased risk of HF hospitalization [36]. The small number of patients receiving SGLT2 inhibitors and GLP-1 inhibitors within our cohort limits us in terms of assessing the impact of these drugs. But, the increased risk in patients with newonset diabetes after adjustment for antidiabetic medication and comorbidity status could be suggestive of an association that is not fully explained by the uncertain safety profile of antidiabetic medication nor the increased comorbidities among patients with new-onset diabetes. Our study underlines the need to further explore risk factors associated with the development of new-onset diabetes in HF patients.

\section{Limitations}

The main limitations of the present study is the lack of information on clinical variables reflecting HF and diabetes severity including ejection fraction, NYHA class and smoking status, vital parameters e.g. heart rate and blood pressure, body mass index, biochemical parameters such as natriuretic peptides (e.g. NT-pro-BNP), glucose levels, hemoglobin A1c and type of diabetes. As we were not able to fully adjust for these possible confounders, residual bias cannot be ruled out. Secondary we lack 


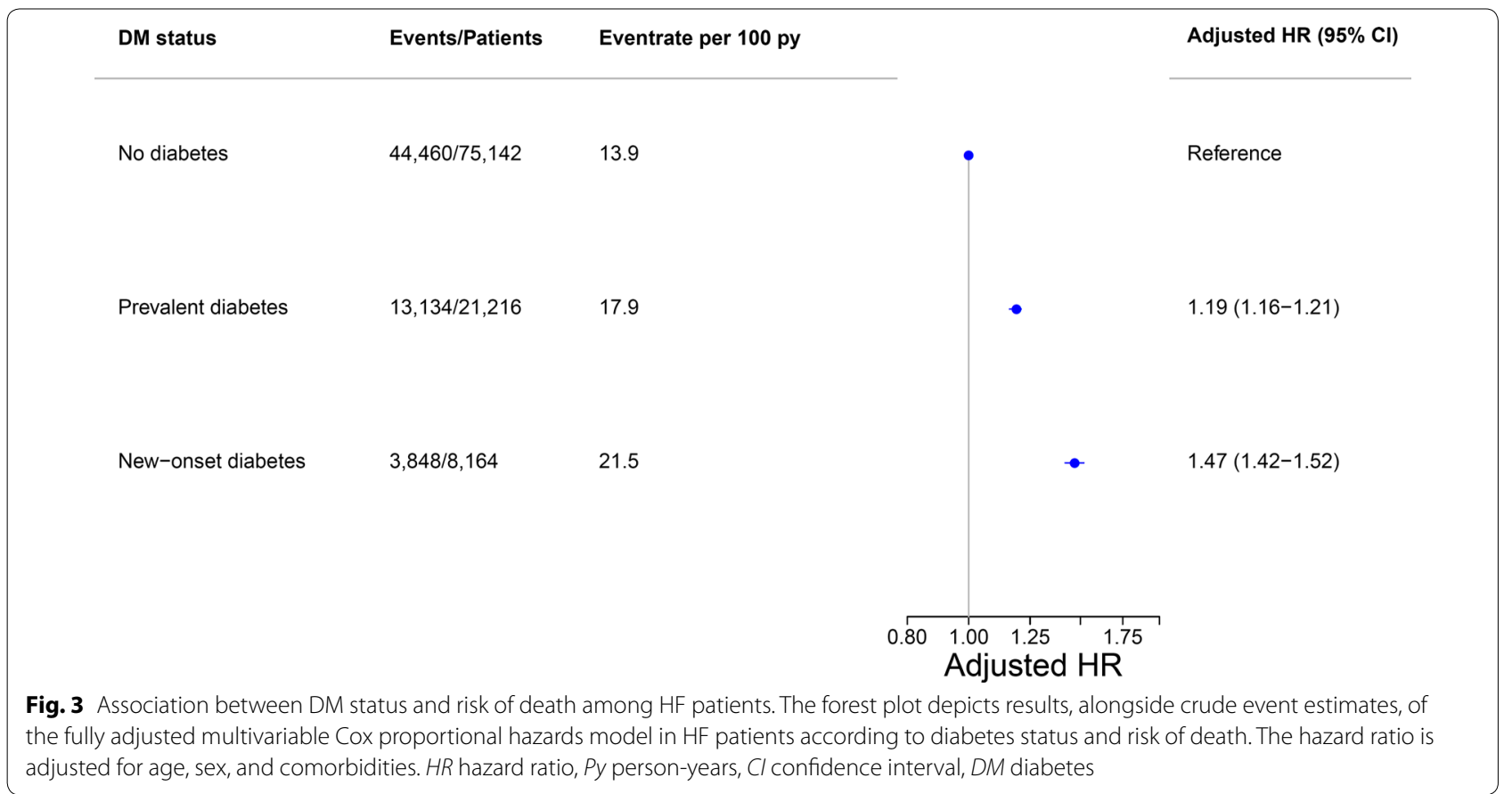

information on diet treated diabetes patients, which confers a selections bias towards a more ill cohort than in the general population.

\section{Clinical implications}

We have shown the impact on prognosis development of new-onset diabetes in patients with HF compared to patients without diabetes. Around $10 \%$ of the HF cohort developed new-onset diabetes and the incidence of new-onset diabetes was rising during follow-up aiding important information from a real-world cohort. We hope our findings will aid clinicians in assessing important subgroups among patients with HF in need of close monitoring and supervision of co-existing diabetes illness.

\section{Conclusion}

Development of new-onset diabetes is common after first HF hospitalization and associated with an increased risk of death compared with HF patients with prevalent as well as no diabetes. Our study underlines the close and detrimental correlation between HF and diabetes and further studies are needed to explore the potential benefit of early diagnosis and improved management of diabetes in the setting of concomitant HF.

\section{Abbreviations}

HF: heart failure; ICD: International classification of diseases; ATC: Anatomical Therapeutic Chemical; ACE: angiotensin-converting enzyme; ARB: angiotensin Il receptor blocker; MRA: mineralocorticoid-receptor antagonist; SD: standard deviation; IQR: interquartile range; HR: hazard ratio; NYHA: New York Heart Association; COMET: Carvedilol or Metoprolol European Trial.

\section{Acknowledgements}

Not applicable.

\section{Authors' contributions}

BZ and SLK analyzed and interpreted the patient data. RR helped with the statistical methods. BZ prepared the manuscript. All authors read and approved the final manuscript.

\section{Funding}

Not applicable.

\section{Availability of data and materials}

The data that support the findings of this study are available from Denmark's Statistics, but restrictions apply to the availability of these data, which were used under license for the current study, and so are not publicly available. Data are however available from the authors upon reasonable request and with permission of Denmark's Statistics.

\section{Ethics approval and consent to participate}

The study was approved by the Danish Data Protection Agency (j-nr. 2007-580015/local.j.nr. GEH-2014-015 I-Suite nr: 02,733). In Denmark, ethical approval is not required for register-based studies.

\section{Consent for publication}

Not applicable.

\section{Competing interests}

The authors declare that they have no competing interests. 


\section{Appendix}

See Table 2.

Table 2 Diagnoses (primary or secondary), surgical procedures, and pharmacotherapy used for defining the study population, comorbidity, concomitant treatment, and outcomes

Details

ICD-8, ICD-10, and ATC codes used

\begin{tabular}{|c|c|c|}
\hline \multicolumn{3}{|l|}{ Study population } \\
\hline Heart failure & $\begin{array}{l}\text { Defined from diagnosis codes including heart failure, cardiomyo- } \\
\text { pathies, hypertensive heart failure }\end{array}$ & $\begin{array}{l}\text { ICD-10: I110, I130, I132, 142, 1426-29, } 150 \\
\text { ICD-8: } 425,428\end{array}$ \\
\hline Diabetes & Defined from treatment with glucose-lowering drugs & ATC: A10 \\
\hline \multicolumn{3}{|l|}{ Comorbidity } \\
\hline Diabetes & & $\begin{array}{l}\text { ICD-10: E10-E14 } \\
\text { ICD-8: } 250\end{array}$ \\
\hline Stroke & & $\begin{array}{l}\text { ICD-10: 160-164 } \\
\text { ICD-8: } 430-434,436\end{array}$ \\
\hline Ischemic heart disease & & $\begin{array}{l}\text { ICD-10: } 121-25 \\
\text { ICD-8: } 410-414\end{array}$ \\
\hline Chronic kidney disease & $\begin{array}{l}\text { Defined from diagnosis codes of chronic glomerulonephritis, } \\
\text { chronic tubulointerstitial nephropathy, chronic kidney disease, } \\
\text { and diabetic and hypertensive nephropathy. }\end{array}$ & $\begin{array}{l}\text { ICD-10: N02-N04, N18-N19, I12, } 113 \\
\text { ICD-8: 582-6, } 588\end{array}$ \\
\hline Atrial fibrillation & & $\begin{array}{l}\text { ICD-10: } 148 \\
42,793,42,793\end{array}$ \\
\hline Cancer & $\begin{array}{l}\text { Defined from all cancer diagnosis codes, excluding non-melanoma } \\
\text { skin cancer }\end{array}$ & $\begin{array}{l}\text { ICD-10: C00-C97 } \\
\text { ICD-8: } 140-209\end{array}$ \\
\hline Chronic obstructive pulmonary disease & & $\begin{array}{l}\text { ICD-10: J42, J44 } \\
\text { ICD-8: 490-492 }\end{array}$ \\
\hline Hypertension & & $\begin{array}{l}\text { ICD 10: } 110-115 \\
\text { ICD-8: } 400-404\end{array}$ \\
\hline \multicolumn{3}{|l|}{ Concomitant pharmacotherapy } \\
\hline Statins & & ATC: C10A \\
\hline Beta-blockers & & ATC: C07 \\
\hline Aldosterone antagonists & & ATC: CO3D \\
\hline Platelet inhibitors & & ATC: B01AC04, BO1AC06 \\
\hline Digoxin & & ATC: C01AA05 \\
\hline Thiazides & & ATC CO3A \\
\hline Renin angiotensin system inhibitors & $\begin{array}{l}\text { Including angiotensin-converting-enzyme inhibitors, angiotensin } \\
\text { II receptor blockers }\end{array}$ & ATC: C09 \\
\hline Loop diuretics & & ATC: C03CA01 \\
\hline Insulin & & ATC: A10A \\
\hline Metformin & & ATC A10BA02 \\
\hline Sulfonylurea & & ATC: A10BB \\
\hline Thiazolide & & ATC: A10BG \\
\hline Dipeptidyl peptidase-4 inhibitor & & ATC: A10BB \\
\hline Glucagon-like peptide-1 & & ATC: A10BG \\
\hline Sodium-glucose co-transporter-2 & & ATC: A10BK \\
\hline Combination of two anti-diabetic drugs & $\begin{array}{l}\text { Either a combination of metformin, sulfonylurea, thiazolidinedione, } \\
\text { dipeptidyl peptidase- } 4 \text { inhibitor, sodium-glucose cotrans- } \\
\text { porter- } 2 \text { or glucagon-like peptide-1 receptor agonist }\end{array}$ & ATC: A10BD \\
\hline
\end{tabular}

Diagnoses (primary or secondary), surgical procedures, and pharmacotherapy used for defining the study population, comorbidity, concomitant treatment, and outcomes

ATC: Anatomical Therapeutic Chemical (ATC) system; ICD-8: 8th revision of the International Classification of Diseases system; ICD-10: 10th revision of the International Classification of Diseases system 


\begin{abstract}
Author details
${ }^{1}$ Department of Cardiology, Herlev and Gentofte University Hospital, Niels Andersens vej 65, Gentofte, 2900 Copenhagen, Denmark. ${ }^{2}$ Department of Cardiology, Righospitalet University Hospital, Copenhagen, Denmark. ${ }^{3}$ Department of Endocrinology, Amager and Hvidovre University Hospital, Copenhagen, Denmark. ${ }^{4}$ Department of Cardiology, Aalborg Hospital, Aalborg, Denmark. ${ }^{5}$ Department of Clinical Investigation and Cardiology, Nordsjaellands Hospital, Hillerød, Denmark.
\end{abstract}

Received: 11 April 2019 Accepted: 3 June 2019

Published online: 12 June 2019

\section{References}

1. Sandesara PB, O'Neal WT, Kelli HM, Samman-Tahhan A, Hammadah M, Quyyumi AA, et al. The prognostic significance of diabetes and microvascular complications in patients with heart failure with preserved ejection fraction. Diabetes Care. 2018:41(1):150. https://doi.org/10.2337/ dc17-0755.

2. Gerstein HC, Swedberg K, Carlsson J, et al. The hemoglobin a1c level as a progressive risk factor for cardiovascular death, hospitalization for heart failure, or death in patients with chronic heart failure: an analysis of the Candesartan in heart failure: assessment of reduction in mortality and morbidity (charm) program. Arch Intern Med. 2008;168(15):1699-704. https ://doi.org/10.1001/archinte.168.15.1699.

3. Skali H, Shah A, Gupta DK, Cheng S, Claggett B, Liu J, et al. Cardiac structure and function across the glycemic spectrum in elderly men and women free of prevalent heart disease: the atherosclerosis risk in the community study. Circulation. 2015;8(3):448-54. https://doi.org/10.1161/circheartfailur e.114.001990.

4. Seferović PM, Paulus WJ. Clinical diabetic cardiomyopathy: a two-faced disease with restrictive and dilated phenotypes. Eur Heart J. 2015;36(27):171827. https://doi.org/10.1093/eurheartj/ehv134.

5. Swan JW, Anker SD, Walton C, Godsland IF, Clark AL, Leyva F, et al. Insulin resistance in chronic heart failure: relation to severity and etiology of heart failure. J Am Coll Cardiol. 1997;30(2):527-32. https://doi.org/10.1016/50735 -1097(97)00185-X

6. ALZadjali MA, Godfrey V, Khan F, Choy A, Doney AS, Wong AK, et al. Insulin resistance is highly prevalent and is associated with reduced exercise tolerance in nondiabetic patients with heart failure. J Am Coll Cardiol, 2009;53(9):747-53. https://doi.org/10.1016/j.jacc.2008.08.081.

7. Demant MN, Gislason GH, Køber L, Vaag A, Torp-Pedersen C, Andersson C. Association of heart failure severity with risk of diabetes: a Danish nationwide cohort study. Diabetologia. 2014;57(8):1595-600. https://doi. org/10.1007/s00125-014-3259-Z

8. Schmidt M, Schmidt SAJ, Sandegaard JL, Ehrenstein V, Pedersen L, Sørensen HT. The Danish National Patient Registry: a review of content, data quality, and research potential. Clin Epidemiol. 2015;7:449. https://doi.org/10.2147/ clep.s91125.

9. Thygesen SK, Christiansen CF, Christensen S, Lash TL, Sørensen HT. The predictive value of ICD-10 diagnostic coding used to assess Charlson comorbidity index conditions in the population-based Danish National Registry of Patients. BMC Med Res Methodol. 2011;11(1):83. https://doi. org/10.1186/1471-2288-11-83.

10. Kristensen JK, Drivsholm TB, Carstensen B, Steding-Jensen M, Green A. Validation of methods to identify known diabetes on the basis of health registers. Ugeskr Laeg. 2007;169(18):1687-92.

11. R Core Team. R: A language and environment for statistical computing. $R$ Foundation for StatisticalComputing, Vienna, Austria. https://www.R-proje ct.org/. Accessed 6 June 2019.

12. Kannel WB, Hjortland M, Castelli WP. Role of diabetes in congestive heart failure: The Framingham study. Am J Cardiol. 1974;34(1):29-34. https://doi. org/10.1016/0002-9149(74)90089-7.

13. Rosano $G M$, Vitale C, Seferovic P. Heart failure in patients with diabetes mellitus. Card Fail Rev. 2017;3(1):52-5. https://doi.org/10.15420/cfr.2016:20:2.

14. Kristensen SL, Preiss D, Jhund PS, Squire I, Cardoso JS, Merkely B, et al. Risk related to pre-diabetes mellitus and diabetes mellitus in heart failure with reduced ejection fraction: insights from prospective comparison of ARNI With ACEl to determine impact on global mortality and morbidity in heart failure trial. Circulation. 2016;9(1):e002560. https://doi.org/10.1161/circheartf ailure.115.002560.

15. Gustafsson F. Long-term survival in patients hospitalized with congestive heart failure: relation to preserved and reduced left ventricular systolic function. Eur Heart J. 2003;24(9):863-70. https://doi.org/10.1016/S0195 $-668 \times(02) 00845-X$

16. Ziaeian B, Hernandez AF, DeVore AD, Wu J, Xu H, Heidenreich PA, et al. Long-term outcomes for heart failure patients with and without diabetes: from the Get With The Guidelines_- Heart Failure Registry. Am Heart J. 2019;211:1-10. https://doi.org/10.1016/j.ahj.2019.01.006.

17. Bouthoorn S, Gohar A, Valstar G, den Ruijter HM, Reitsma JB, Hoes AW, et al. Prevalence of left ventricular systolic dysfunction and heart failure with reduced ejection fraction in men and women with type 2 diabetes mellitus: a systematic review and meta-analysis. Cardiovasc Diabetol. 2018. https:// doi.org/10.1186/s12933-018-0690-3.

18. Costanzo P, Cleland JGF, Pellicori P, Clark AL, Hepburn D, Kilpatrick ES, et al. The obesity paradox in type 2 diabetes mellitus: relationship of body mass index to prognosis: a cohort study. Ann Intern Med. 2015;162(9):610. https:// doi.org/10.7326/M14-1551.

19. Lee KS, Moser DK, Lennie TA, Pelter MM, Nesbitt T, Southard JA, et al. Obesity paradox: comparison of heart failure patients with and without comorbid diabetes. Am J Crit Care. 2017;26(2):140-8. https://doi.org/10.4037/ajcc2 017634.

20. Zadok OIB, Kornowski R, Goldenberg I, Klempfner R, Toledano Y, Biton Y, et al. Admission blood glucose and 10-year mortality among patients with or without pre-existing diabetes mellitus hospitalized with heart failure. Cardiovasc Diabetol. 2017;16:102. https://doi.org/10.1186/s12933-017-0582-y.

21. Gustafsson F. Female sex is associated with a better long-term survival in patients hospitalized with congestive heart failure. Eur Heart J. 2004;25(2):129-35. https://doi.org/10.1016/j.ehj.2003.10.003.

22. Torp-Pedersen C, Metra M, Charlesworth A, Spark P, Lukas MA, Poole-Wilson PA, et al. Effects of metoprolol and carvedilol on pre-existing and new onset diabetes in patients with chronic heart failure: data from the Carvedilol Or Metoprolol European Trial (COMET). Heart. 2007;93(8):968-73. https://doi. org/10.1136/hrt.2006.092379.

23. Preiss D, van Veldhuisen DJ, Sattar N, Krum H, Swedberg K, Shi H, et al. Eplerenone and new-onset diabetes in patients with mild heart failure: results from the Eplerenone in Mild Patients Hospitalization and Survival Study in Heart Failure (EMPHASIS-HF). Eur J Heart Fail. 2012;14(8):909-15. https://doi.org/10.1093/eurjhf/hfs067.

24. Preiss D, Zetterstrand S, McMurray JJV, Ostergren J, Michelson EL, Granger $\mathrm{CB}$, et al. Predictors of development of diabetes in patients with chronic heart failure in the Candesartan in Heart Failure Assessment of Reduction in Mortality and Morbidity (CHARM) Program. Diabetes Care. 2009;32(5):91520. https://doi.org/10.2337/dc08-1709.

25. Forouhi NG, Luan J, Hennings S, Wareham NJ. Incidence of type 2 diabetes in England and its association with baseline impaired fasting glucose: The Ely study 1990-2000. Diabet Med. 2007;24(2):200-7. https://doi.org/10.111 1/j.1464-5491.2007.02068.x.

26. Tenenbaum A, Motro M, Fisman EZ, Leor J, Freimark D, Boyko V, et al. Functional class in patients with heart failure is associated with the development of diabetes. Am J Med. 2003;1 14(4):271-5. https://doi.org/10.1016/S0002 -9343(02)01530-9.

27. Mohamedali B, Yost G, Bhat G. Mechanical circulatory support improves diabetic control in patients with advanced heart failure: improvement in diabetes with LVAD. Eur J Heart Fail. 2014;16(10):1120-4. https://doi. org/10.1002/ejhf.166.

28. Schmiegelow M, Andersson C, Olesen JB, Abildstrom SZ, Kober L, TorpPedersen C. Body mass index is closely correlated to incident diabetes in patients with heart failure or myocardial infarction. Eur J Cardiovasc Prevent Rehabil. 2011;18(2):305-11. https://doi.org/10.1177/1741826710389420.

29. Kostis J, Sanders M. The association of heart failure with insulin resistance and the development of type 2 diabetes. Am J Hypertens. 2005;18(5):731-7. https://doi.org/10.1016/.j.amjhyper.2004.11.038.

30. Paolisso G, De Riu S, Marrazzo G, Verza M, Varricchio M, D'Onofrio F. Insulin resistance and hyperinsulinemia in patients with chronic congestive heart failure. Metabolism. 1991;40(9):972-7. https://doi.org/10.1016/00260495(91)90075-8

31. Thuesen ACB, Vaag A. Perspectives on diabetes mortality as the result of residual confounding and reverse causality by common disease. Diabetes Obes Metab. 2018;20(6):1342-9. https://doi.org/10.1111/dom.13238. 
32. Ridker PM, Everett BM, Thuren T, MacFadyen JG, Chang WH, Ballantyne $C$ et al. Antiinflammatory therapy with canakinumab for atherosclerotic disease. N Engl J Med. 2017;377(12):1119-31. https://doi.org/10.1056/NEJMo a1707914.

33. Zhao W, Rasheed A, Tikkanen E, Lee J-J, Butterworth AS, Howson JMM, et al. Identification of new susceptibility loci for type 2 diabetes and shared etiological pathways with coronary heart disease. Nat Genet. 2017;49(10):14507. https://doi.org/10.1038/ng.3943.

34. Ross S, Gerstein HC, Eikelboom J, Anand SS, Yusuf S, Paré G. Mendelian randomization analysis supports the causal role of dysglycemia and diabetes in the risk of coronary artery disease. Eur Heart J. 2015;36(23):1454-62. https:// doi.org/10.1093/eurheartj/ehv083.

35. Nesto RW. Thiazolidinedione use, fluid retention, and congestive heart failure: a consensus statement from the American Heart Association and
American Diabetes Association. Circulation. 2003;108(23):2941-8. https:// doi.org/10.1161/01.CIR.0000103683.99399.7E.

36. Gautam S, Agiro A, Barron J, Power T, Weisman H, White J. Heart failure hospitalization risk associated with use of two classes of oral antidiabetic medications: an observational, real-world analysis. Cardiovasc Diabetol. 2017;16:93. https://doi.org/10.1186/s12933-017-0575-x.

\section{Publisher's Note}

Springer Nature remains neutral with regard to jurisdictional claims in published maps and institutional affiliations.
Ready to submit your research? Choose BMC and benefit from:

- fast, convenient online submission

- thorough peer review by experienced researchers in your field

- rapid publication on acceptance

- support for research data, including large and complex data types

- gold Open Access which fosters wider collaboration and increased citations

- maximum visibility for your research: over $100 \mathrm{M}$ website views per year

At BMC, research is always in progress.

Learn more biomedcentral.com/submissions 